\title{
Ultrafast heating by high efficient biomass direct mixing with supercritical water.
}

Luis Vaquerizo ${ }^{\text {a }}$, María José Cocero ${ }^{\mathrm{a}, *}$

Bioecouva Research Institute. High Pressure Processes Group, Department of

Chemical Engineering and Environmental Technology, University of Valladolid (Spain).

* Corresponding author. Tel: +34 983423174; fax: +34 983423013.

E-mail addresses: lvaquerizo@iq.uva.es (L.VVaquerizo), mjcocero@iq.uva.es (M.J.

Cocero)

\begin{abstract}
This work analyzes the influence of the mixer configuration on the mixing efficiency in the process of biomass ultrafast hydrolysis by supercritical water. The results of the CFD simulations of a horizontal tee, a vertical tee and a mixing cross, selected as the optimum mixing configurations, together with the experimental results obtained in our hydrolysis plant, are the base to determine the configuration which provides the best mixing performance. Although slightly higher conversions are obtained in those experiments performed with a horizontal tee, the small differences between the results demand a theoretical analysis. Therefore, according to the CFD simulation results, since the mixing cross provides the best flow distribution and temperature homogenization at the outlet of the mixers and because of the great similarity between the residence time distribution curves of the mixers, the mixing cross is selected as the optimum geometry to perform the mixing.
\end{abstract}

Keywords: CFD Simulation, Turbulence, Buoyancy Effects, Biomass Particle, Temperature Profile, Streamlines. 
Declarations of interest: None 


\section{Introduction}

The ultrafast hydrolysis of biomass by supercritical water allows effectively obtaining chemicals from biomass [1]. This technology, based on drastic reaction conditions $\left(\mathrm{T}=400^{\circ} \mathrm{C}, \mathrm{P}=250 \mathrm{bara}\right)$ and on reduced reaction times (reaction times lower than $1 \mathrm{~s}$ ), allows obtaining selectivity values over $90 \%[2,3]$. Because of the drastic reaction conditions, an uncontrolled increase in the hydrolysis time would produce the complete degradation of the final products $[4,5]$. Therefore, a detailed analysis of the performance of all the pieces of equipment which influence this parameter is required.

The objectives of the main studies performed on biomass hydrolysis by supercritical water have been related to the obtaining of the optimal reaction conditions (pressure, temperature and reaction time) [3], the understanding of the reaction pathways and the development of accurate kinetic models [6-9]. Since the results of these works have provided a clear insight on the fundamentals of the process, the current studies are focused on the scale up of the process [10]. Although, some works related with the downstream process alternatives, mainly focused on the improvement of the energetic efficiency of the process, have been already presented [11,12], the influence of the mixer configuration on the final performance of the process has not been analyzed. An effective mixing of the biomass suspension and the supercritical water stream achieves a homogeneous distribution of the biomass particles, avoids temperature differences at the inlet of the hydrolysis reactor and minimizes the mixing time and consequently, the degradation of the biomass particles and the generation of byproducts before the reactor. While a homogeneous dispersion of the biomass particles facilitates the attack of the water molecules to the biomass network, the existence of temperature differences in the radial direction of the reactor penalizes the selectivity of the process because of the promotion of side reactions [6]. 
Because of the drastic reaction conditions, the reduced reaction times and the opacity of the reactors, the acquisition of experimental data to determine the mixing profiles is greatly limited. Consequently, innovative techniques such as the neutron radiography [13], the use of high pressure optical cells [14], the light absorption imaging [15] or the direct visualization in transparent reactors [16] have been successfully applied. Although these studies were aimed to analyze the mixing behavior in processes such as hydrothermal synthesis of particles and supercritical water oxidation, they must be considered as the base to analyze the mixing performance in biomass ultrafast hydrolysis.

A powerful tool used in the analysis of fluid flow patterns and mixing performance is computational fluid dynamics (CFD). There are currently some examples which have already considered CFD to determine the optimum mixing configuration in processes which involve supercritical fluids [17,18]. First, in the hydrothermal synthesis of particles, CFD has been successfully applied to determine the optimum mixing geometry [19], to quantify the mixing efficiency [20] and to correlate the particle size distribution (PSD) with the reaction time [21]. Secondly, in supercritical water oxidation, CFD techniques have been applied to the analysis of the relationships between the mixing dynamics and the minimization of corrosion [16] and the mixing effects and the oxidation kinetics [22].

This work analyzes the mixing behavior in the process of biomass ultrafast hydrolysis by supercritical water comparing the experimental results obtained in the hydrolysis plant of our research group with the theoretical results obtained in the CFD simulations of the mixers. The main objective of this work is to determine the optimum geometry to perform the mixture between the biomass suspension stream and the supercritical water stream minimizing the presence of degradation products at the inlet of the hydrolysis 
reactor. Therefore, several parameters as the geometry of the mixer and the influence of the turbulent and buoyancy forces are studied in detail.

\section{Materials and Methods}

\subsection{Materials}

Deionized water and high purity microcrystalline cellulose purchased from VWR (A17730) were used to perform the experiments.

\subsection{Analysis}

The solid fraction at the outlet of the reactor, which represents the unconverted cellulose, was determined by gravimetric analysis. This fraction was immediately separated by centrifugation from the product samples, dried at $60^{\circ} \mathrm{C}$ during 24 hours and finally weighted. Then, cellulose conversion in the reactor was determined by Equation 1:

Equation 1: $\mathrm{X}=\frac{\mathrm{W}_{0}-\mathrm{W}}{\mathrm{W}_{0}}$

Where $\mathrm{X}$ represents cellulose conversion, $\mathrm{W}_{0}$ the cellulose mass concentration at the inlet of the reactor (g cellulose / $\mathrm{g}$ total) and $\mathrm{W}$ the cellulose mass concentration at the outlet of the reactor ( $\mathrm{g}$ cellulose / $\mathrm{g}$ total).

\subsection{Experimental Setup}

All the experiments were carried out in the FASTSUGARS continuous pilot plant whose process flow diagram and a detailed description of its operation methodology can be found in previous works of our research group [9,23]. Briefly, a water stream which 
is pressurized and heated over the critical point is mixed with a pressurized cellulose suspension stream. The reaction time, key parameter of the process which remains below 1s, is controlled varying both the fed streams flowrates and the reactor volume. Finally, an expansion valve located immediately after the reactor depressurizes the product stream decreasing the reaction temperature and stopping the hydrolysis reactions.

In this work, a pressure of $25 \mathrm{MPa}$ and operating temperatures of $375^{\circ} \mathrm{C}$ and $385^{\circ} \mathrm{C}$ were selected as reaction conditions at the inlet of the reactor. Additionally, two different flowrates, $4.8 \mathrm{~kg} / \mathrm{h}$ and $6 \mathrm{~kg} / \mathrm{h}$ of mixture of cellulose suspension and supercritical water, were considered. Finally, in all the experiments the cellulose suspension concentration remained constant at $5 \% \mathrm{w} / \mathrm{w}, 1.7 \% \mathrm{w} / \mathrm{w}$ at the inlet of the reactor.

\section{Model description}

\subsection{CFD simulations overview}

The aim of the CFD simulations presented in this work and performed in the commercial software Ansys Fluent 17.0 is to provide a theoretical insight of the mixing behavior in the process of biomass ultrafast hydrolysis by supercritical water. Because of the higher versatility of the CFD simulations compared to the operation in the experimental plant, the use of this computational tool allows easily analyzing the influence of the turbulent and buoyancy effects (forced and natural convection) $[16,18]$. Therefore, apart from the flowrates tested in the hydrolysis plant, the effect of operating with higher flowrates has been also studied.

The buoyancy effects become more relevant as the difference between the densities of the mixed fluids increases. This application is clearly an example in which the buoyancy effects must be considered. While the density of supercritical water is equal to 
$90 \mathrm{~kg} / \mathrm{m}^{3}$ at the inlet of the mixer $\left(\mathrm{P}=250 \mathrm{bara}\right.$ and $\left.\mathrm{T}=500^{\circ} \mathrm{C}\right)$, the density of the pressurized ambient water is equal to $1009 \mathrm{~kg} / \mathrm{m}^{3}\left(\mathrm{P}=250 \mathrm{bara}\right.$ and $\left.\mathrm{T}=20^{\circ} \mathrm{C}\right)$. Regarding the forced convection, it is mainly determined by the physical properties (density and viscosity) and by the velocity of the mixed fluids. Numerically, the Richardson number, defined by Equation 2, is commonly used to determine whether the mixing behavior is mainly influenced by the forced or the natural convection or if both effects must be considered. While Richardson numbers higher than one indicate that the flow pattern is mainly determined by the buoyancy effects because of the predominance of natural convection, values lower than one indicate a predominance of the forced convection. Finally, in the cases in which the Richardson number is close to one, the influence of both effects must be considered.

Equation 2: $R i=G r / R e^{2}$

where Gr represents the Grashof number defined by Equation 3 and Re the Reynolds number defined by Equation 4:

Equation 3: $G r=\frac{g \cdot \beta \cdot \Delta T \cdot \delta^{3}}{v^{2}}$

where $\mathrm{g}$ is the gravitational acceleration, $\beta$ is the thermal expansion coefficient of the supercritical water, $\Delta \mathrm{T}$ is the temperature difference between the supercritical water stream temperature and the ambient temperature $\left(500^{\circ} \mathrm{C}\right.$ and $\left.20^{\circ} \mathrm{C}\right), \delta$ is the characteristic dimension, in this case the inlet diameter, and $v$ is the kinematic viscosity of the supercritical water. 
Equation 4: $R e=\frac{u \cdot D \cdot \rho}{\mu}$

where $\mathrm{u}$ is the velocity of the supercritical water stream, D is the inlet diameter and $\rho$ and $\mu$ are respectively the density and the viscosity of the supercritical water.

\subsection{Boundary conditions}

In the simulations presented in this work, the reaction conditions $\left(250 \mathrm{bara} \& 390^{\circ} \mathrm{C}\right)$ have been selected considering the optimum hydrolysis conditions defined in a previous work of our research group [3]. A supercritical water stream at $500^{\circ} \mathrm{C}$ and $250 \mathrm{bara}$ is mixed with a biomass suspension stream at $20^{\circ} \mathrm{C}$ and 250 bara. To simplify the simulation and because of the low pressure drop in the mixer $(\Delta \mathrm{P}<0.2$ bara $)$ compared with the static pressure of the inlet streams $(\mathrm{P}=250 \mathrm{bara})$, the influence of the pressure drop on the variation of the physical properties has been neglected. Moreover, because of the low biomass concentrations considered in the biomass suspension streams $(5 \%$ $\mathrm{w} / \mathrm{w}$ in this case), and the fact that the biomass particles are partially dissolved, the biomass suspension stream has been simulated as an ambient water stream neglecting the presence of solid particles. This simplification reduces the complexity and the calculation time of the CFD simulations since the selection of a multiphase model is not required. Regarding the mass flowrates of both streams, two different scenarios with the same relationship between the flowrates of supercritical water and of biomass suspension are selected to analyze the effect of the turbulent and buoyancy forces. While in the first scenario the mass flowrates are fixed at $4.8 \mathrm{~kg} / \mathrm{h}$ and $1.6 \mathrm{~kg} / \mathrm{h}$ indicating that both the buoyancy and the turbulent effects must be considered $(\mathrm{Ri}=0.5)$, in the second scenario the mass flowrates are increased up to $62 \mathrm{~kg} / \mathrm{h}$ and $186 \mathrm{~kg} / \mathrm{h}$ which results in a predominance of the forced convection $\left(\mathrm{Ri}=3 \cdot 10^{-4}\right)$. 
In the CFD simulations, the mass flowrates of the supercritical water stream and of the cold water stream used to model the biomass suspension stream were fixed as inlet boundary conditions. Furthermore, the zero pressure condition was selected at the outlet of the reactor. As thermal boundary conditions, while the temperature of the inlet streams were fixed at the inlets of the mixers, the walls were modeled as adiabatic solids.

\subsection{Physical properties}

The drastic variations of the physical properties of water in the vicinities of the critical point demand a robust thermodynamic model which does not generate calculation divergences during the iterations of the CFD simulation. Considering that in this case the two streams which are mixed are modeled as water streams, the properties of water can be directly determined from the water and stream tables provided by the International Association for the Properties of Water and Steam (IAPWS). In this simulation, instead of implementing the tables by means of an User Defined Function (UDF), Ansys Fluent is connected to Aspen Plus, which already contains these tables, by means of the interconnecting method created by our research group [24]. When Ansys Fluent requires the value of a physical property, it is connected to Aspen Plus returning the desired value.

\subsection{Turbulence model}

In a CFD simulation, the flow pattern is obtained solving the mass, momentum and energy conservation equations. When turbulent flows are present, the selection of an accurate turbulence model able to characterize the fluid behavior is always required. In this work, considering that in some sections of the mixer the Reynolds number variates 
between $10^{3}$ and $10^{4}$ and that therefore, the fluid is in the transition regime [25], the Transition SST turbulence model has been selected. This four equations model, suitable for the transition regime, is based on the coupling between the SST k- $\omega$ turbulence model and two additional transport equations [26]. The SST k- $\omega$ model, which is the base of the Transition SST model, is considered as the best turbulence model to reproduce complex flows because of its ability predicting separation and modeling adverse pressure gradients [27]. Finally, regarding the value of the $y+$ parameter, it remained below 40 in all the simulations.

\subsection{CAD models, mesh description and simulations resolution}

The CAD models of the mixers simulated in this work have been directly obtained from the commercial website of Hoke®. Two tee type mixers, the first one with inlets and outlet diameters of 1/8 inch and the second one with inlets and outlet diameters of 1/4 inch, and a cross type mixer with inlets and outlet of 1/4 inch have been selected. While the $1 / 8$ inch tee type mixer has been used in the validation of the model, the $1 / 4$ inch tee type mixer and the $1 / 4$ cross type mixer have been selected to perform the analysis of the optimum geometry and of the forced and natural convection effects. In this work, it has been considered that after reaching a stationary operation and because of the existence of an effective isolation, the influence of the temperature difference between the outer and the inner walls of the mixers can be neglected. Therefore, only the internal part of the mixers has been modeled. Moreover, because of the existence of a symmetry plane, only half of the mixers has been considered reducing the computational time required in each simulation.

The three dimensional CAD models of the mixers were meshed with hexahedral elements, increasing the mesh density in the central section where the initial contact 
between both streams is produced. After successive coarsening and refinement of the meshes, the independence between the numerical solution and the mesh size was reached with a mesh of around 350000 elements. Figure 1 shows the CAD representation of the three mixers considered in this work and a detail of the meshes in the central sections of the mixers.

a)
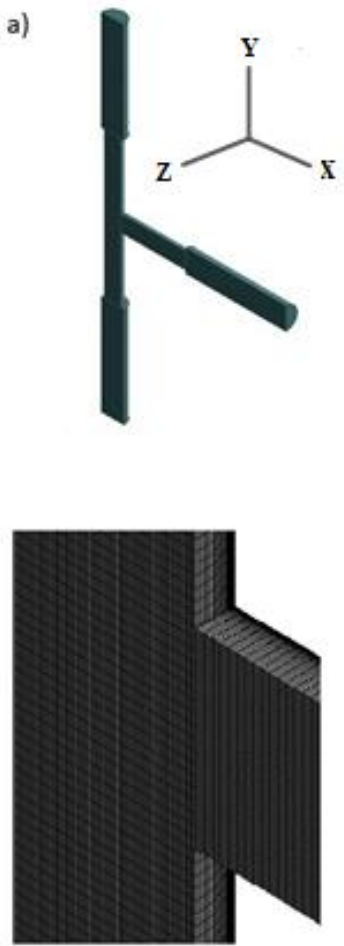

b)
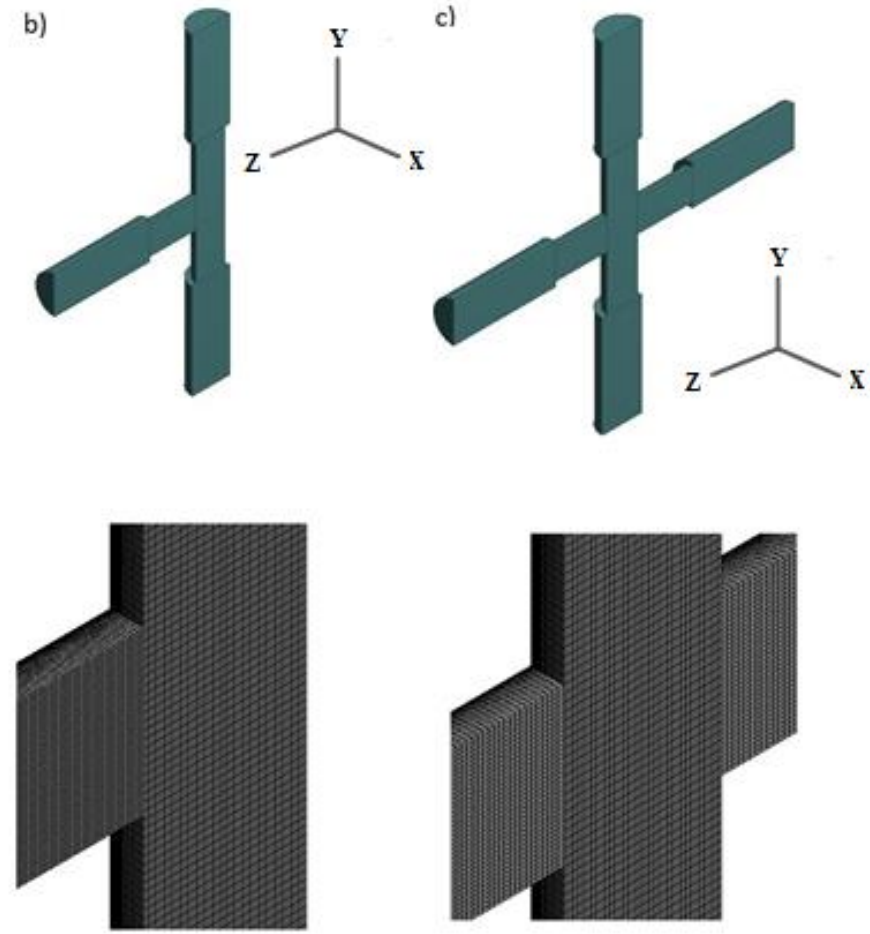

Figure 1: CAD representations of the mixers simulated in this work and details of the corresponding meshes in the central sections. a) $1 / 8$ tee type mixer. b) $1 / 4$ tee type mixer. c) $1 / 4$ cross type mixer.

Regarding the numerical resolution of the simulations, the Coupled algorithm was selected as pressure velocity coupling scheme. The transport and thermodynamic equations were solved selecting first order upwind schemes and when the solution was converged, second order schemes. 
3.6 Residence time distribution curves (RTD)

An analysis of the residence time distribution curves (RTD) of the mixers can reveal the existence of preferential pathways and dead zones. In supercritical water hydrolysis, the reduced mixing times drastically increase the complexity of experimentally determining the RTD curves. Therefore, in this work, the impulse experiment was theoretically modelled by means of the injection of a virtual tracer at the biomass inlet during $0.0001 \mathrm{~s}$. The tracer concentration at the outlet of the mixers was determined solving a scalar transport equation over the calculated flow fields considering that the diffusion coefficient of the tracer is equal to its turbulent diffusivity. The evolution of this parameter allows obtaining the RTD curves following the theory developed by Danckwerts [28].

\section{Results and discussion}

\subsection{Mixing geometries}

In this work, two tee type mixers and a mixing cross (Figure 2;Error! No se encuentra el origen de la referencia.) are selected as the optimum geometries to perform the mixture of the feed streams. Although additional mixing geometries, presented in the appendix of this work, have been analyzed, the selection of these configurations is consistent with the geometries considered in previous works [13-16,18,19]. In these works it was observed that when one mixer inlet is located in the horizontal plane and the other one in the vertical plane, because of the forced convection effects and after the mixing point, the stream with the lowest flowrate is pushed towards the region of the outlet tube which is located in the opposite side of the inlet of the fluid with the highest flow. Therefore, in this work, while in the first geometry, a horizontal tee, both streams 
are mixed in countercurrent and their respective inlets are located in the horizontal plane, in the second geometry, a vertical tee, the streams are also mixed in countercurrent but their respective inlets are located in the vertical plane. Finally, in the third geometry, a cross mixer, although the supercritical water stream is divided in two equal streams whose inlets are located in the horizontal plane and the ambient water inlet is located in the vertical plane, a neutralization of this effect is expected when the two countercurrent supercritical water streams are joined in the central section of the mixer. 


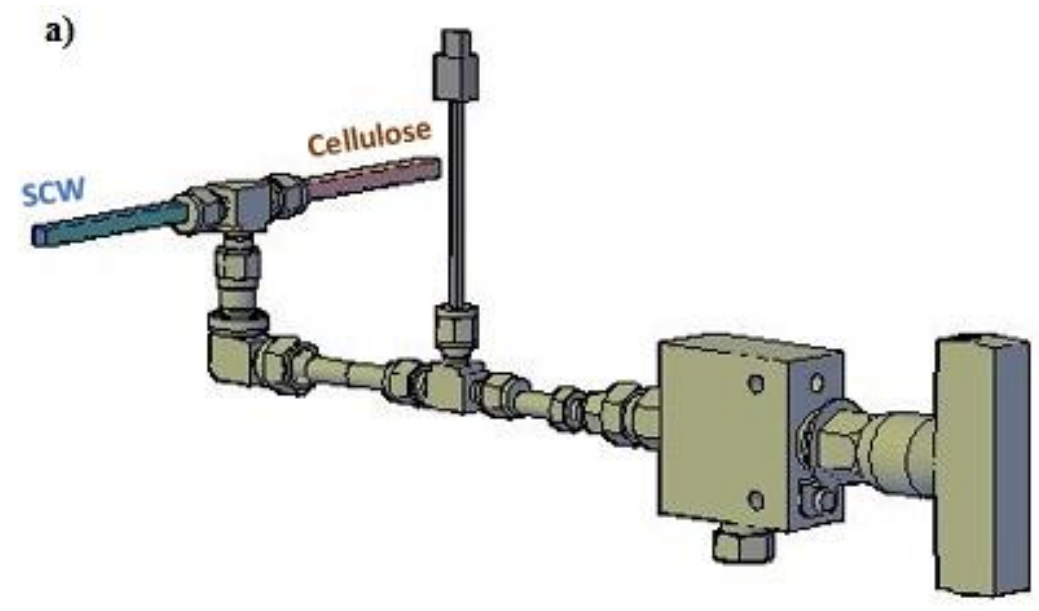

b)

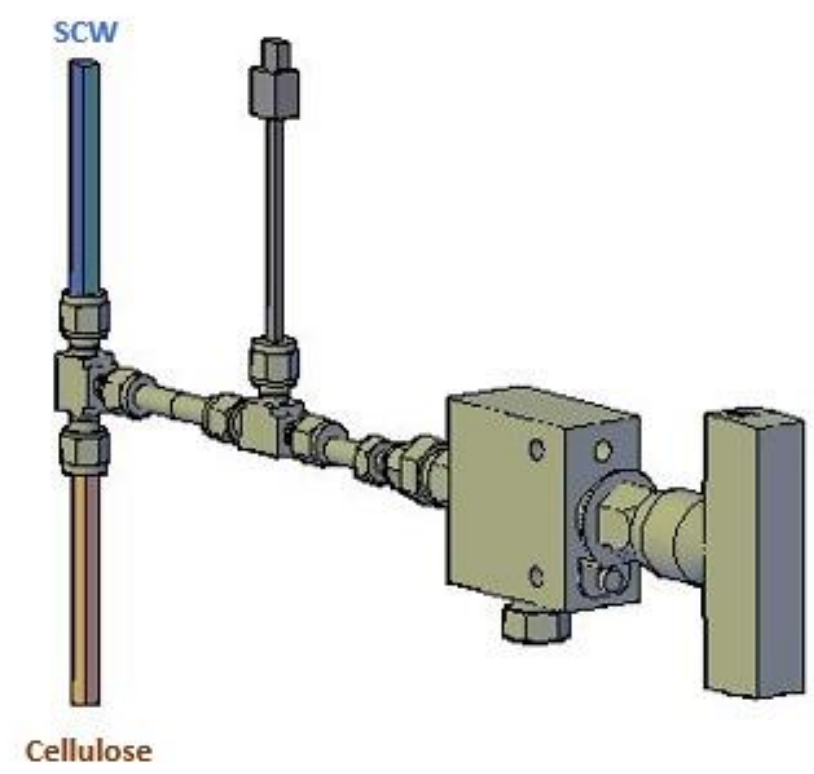

c)

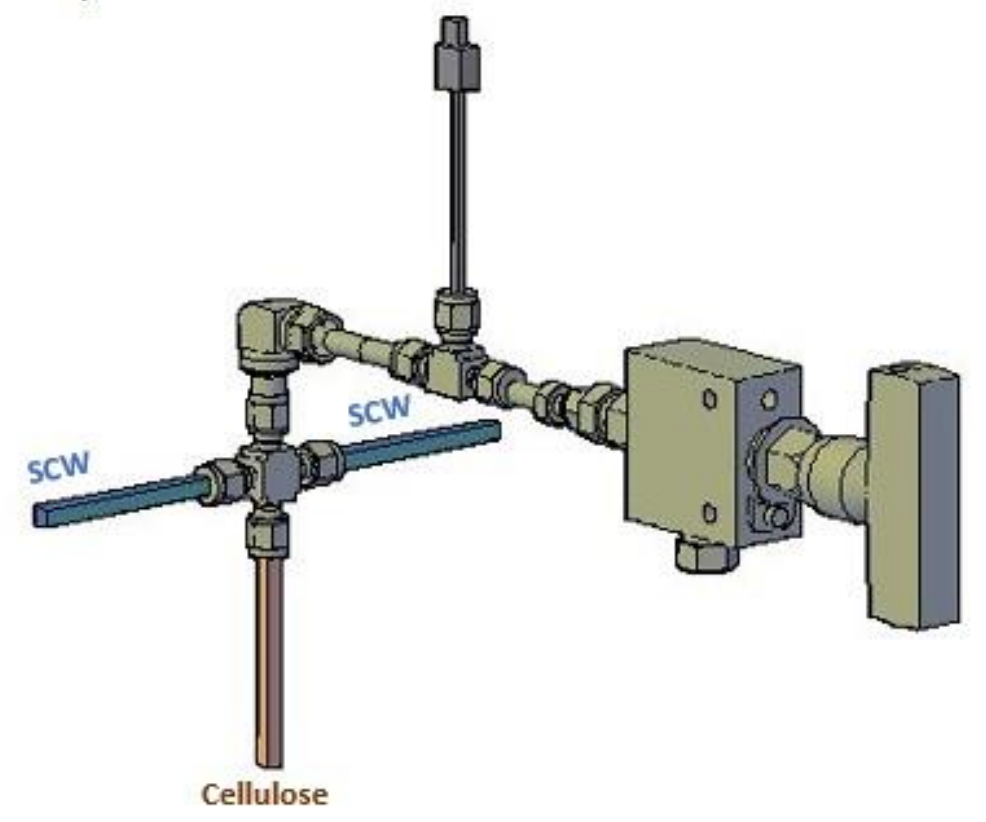


Figure 2: Mixer configurations analyzed in this work. a) Horizontal tee mixer. b) Vertical tee mixer. c) Vertical tee mixer.

In the first mixer, called in this work horizontal tee mixer, the outlet is located at the bottom of the mixer. In this geometry, because of the strong influence of the buoyancy effects, it is expected that the supercritical water will flow towards the top of the mixer. Locating the outlet at the bottom of the mixer, which forces the supercritical water stream to flow downwards, will partially counteract the buoyancy effects. This disposition has been already selected and analyzed by other authors [13-15] in similar working conditions.

Regarding the second mixer, called in this work vertical tee mixer, while the supercritical water stream enters in the mixer through the top of the mixer, the ambient water stream enters through its bottom. This selection is based on the same criteria followed in the horizontal tee mixer. Since relevant buoyancy effects are expected, forcing the supercritical water stream to flow downward the mixer will reduce the possible areas of backmixing and recirculation created in the ambient water inlet section. Some authors [19,21] have already analyzed this mixing disposition in similar conditions.

Finally, in the third mixer, called in this work the cross mixer, the ambient water stream enters through the bottom of the mixer because it is considered as the optimum location regarding the flow pattern of the particles. If the biomass suspension stream enters through an inlet located in the horizontal plane and the supercritical water through an inlet located in the vertical plane, the biomass particles could be severely affected by the gravity force. In some cases, especially when the supercritical water flowrate is elevated compared to the biomass suspension flowrate, the particles could fall towards the 
bottom sections of the mixer tubes, increasing the particle concentration in these zones and consequently decreasing the hydrolysis rate. In this work, since the particles enter through the bottom of the mixer, it is expected that the buoyancy effects created inside the mixer will be partially compensated by the gravity force, suspending the biomass particles in the outlet stream and facilitating their hydrolysis.

\subsection{Experimental results}

The influence of the mixing configuration on cellulose hydrolysis has been quantified comparing the cellulose conversions obtained after performing cellulose hydrolysis in each of the three mixing configurations selected. In these experiments, while two reaction temperatures, $\mathrm{T}=375^{\circ} \mathrm{C}$ and $\mathrm{T}=385^{\circ} \mathrm{C}$, and two total flows, $4.8 \mathrm{~kg} / \mathrm{h}$ and $6 \mathrm{~kg} / \mathrm{h}$, have been tested, the reaction pressure $(\mathrm{P}=250$ bara), the cellulose suspension concentration $(5 \% \mathrm{w} / \mathrm{w})$ and the reactor volume remained constant. As explained in Section 3.1, at these working conditions both the turbulent and the buoyancy effects must be considered $(\mathrm{Ri}=0.5)$. Table 1 shows the cellulose conversion values, calculated by Equation 1, obtained with each mixing configuration at the different reaction conditions tested in our hydrolysis plant:

Experiment 1: Tset $=375^{\circ} \mathrm{C}$, Flow $=4.8 \mathrm{~kg} / \mathrm{h}$

\begin{tabular}{lcccc}
\hline ID & Mixer & $\mathbf{T}\left({ }^{\circ} \mathbf{C}\right)$ & $\operatorname{tr}(\mathbf{m s})$ & $\mathbf{X}(\boldsymbol{\%})$ \\
\hline 1.A & Horizontal Tee & 383.4 & 150 & $67 \pm 5.5$ \\
1.C & Cross & 378.4 & 224 & $54 \pm 4.4$ \\
\hline \multicolumn{5}{c}{ Experiment 2: $\mathbf{T s e t}=\mathbf{3 8 5}^{\circ} \mathbf{C}, \mathbf{F l o w}=\mathbf{4 . 8 k g} / \mathbf{h}$} \\
\hline ID & Mixer & $\mathbf{T}\left({ }^{\circ} \mathbf{C}\right)$ & $\operatorname{tr}(\mathbf{m s})$ & $\mathbf{X}(\boldsymbol{\%})$ \\
\hline 2.A & Horizontal Tee & 386.7 & 134 & $77 \pm 2.3$ \\
2.B & Vertical Tee & 384.0 & 180 & $71 \pm 5.9$ \\
2.C & Cross & 384.2 & 193 & $61 \pm 7.2$ \\
\hline \multicolumn{5}{c}{ Experiment 3: $\mathbf{T s e t}=\mathbf{3 7 5}^{\circ} \mathbf{C}, \mathbf{F l o w}=\mathbf{6 k g} / \mathbf{h}$} \\
\hline ID & Mixer & $\mathbf{T}\left({ }^{\circ} \mathbf{C}\right)$ & $\operatorname{tr}(\mathbf{m s})$ & $\mathbf{X}(\boldsymbol{\%})$ \\
\hline 3.A & Horizontal Tee & 379.5 & 130 \\
3.B & Vertical Tee & 374.1 & 172 \\
3.C & Cross & 376.9 & 182 \\
\hline \multicolumn{5}{c}{}
\end{tabular}




\begin{tabular}{ccccc} 
ID & Mixer & $\mathbf{T}\left({ }^{\circ} \mathbf{C}\right)$ & $\operatorname{tr}(\mathbf{m s})$ & $\mathbf{X}(\boldsymbol{\%})$ \\
\hline 4.A & Horizontal Tee & 384.1 & 121 & $62 \pm 6.6$ \\
4.B & Vertical Tee & 380.8 & 165 & $66 \pm 3.1$ \\
4.C & Cross & 383.3 & 156 & $61 \pm 1.1$ \\
\hline
\end{tabular}

Table 1: Analysis of mixer configuration influence. Reaction temperature $\left({ }^{\circ} \mathrm{C}\right)$, reaction time (ms) and cellulose conversions (\%) after hydrolysis.

Although slight deviations in the reaction temperatures and reaction times can be found in Table 1, the analysis of this data can provide an experimental insight on the influence of the mixing configuration. The variations in the reaction times are basically produced by the temperature differences which, in the vicinities of the critical point, severely affect the density of water, the volumetric flows and the reaction times. Because of the extremely high values of the specific heat in this region, although the temperature is controlled by means of a PID which variates the electric power released by the electric heater, obtaining a stabilized temperature will require unreasonably long operating times. Moreover, the operation at higher temperatures, which is not so drastically affected by the variation of the specific heat, is limited by the maximum temperature which can be reached without damaging the expansion valve.

As it can be seen from Table 1, the maximum experimental conversions are obtained in those experiments with the highest operating temperature (considering the lower reaction times). Therefore, it can be concluded that, at least at these working concentrations, the conversion is more affected by the reaction temperature than by the configuration of the mixer. Moreover, comparing the experiments 1.A with 4.C and 2.B with 2.C, which have similar reaction temperatures and times, it is observed that the conversion is higher in those cases in which a mixing tee was considered. This can be a consequence of the higher complexity of installing a mixing cross and the fact that if the 
tubes which connect the supercritical water splitter with the mixing cross are not completely symmetrical, a preferential pathway can be created penalizing the effectiveness of the mixture. Finally, comparing the experiments $2 . \mathrm{B}$ and 4 .A, which have practically the same reaction temperature, the mixing effectiveness is higher in the case of the horizontal mixing tee than in the vertical mixing tee.

Although the experimental results presented in this work reveal that slightly higher cellulose conversions are obtained in those experiments performed with a horizontal tee, the small differences between the results demand a theoretical analysis to clarify the influence of the different configurations in the mixing performance.

\subsection{CFD model validation}

The validation of the numerical model presented in this work has been performed comparing an experimental mixing profile obtained by researchers of the Department of Chemical Engineering of the University of Tohoku [13] with the theoretical results predicted by the model. In that work, the authors analyzed the influence of the geometry and of the mass flowrates on the mixture of a supercritical water stream and a cold water stream performed in a tee type mixer of $1 / 8$ inch. While the temperature of the hot water stream was fixed at $384^{\circ} \mathrm{C}$ and the flowrate was varied between 8 and $12 \mathrm{~g} / \mathrm{min}$, ambient water with a flowrate between 1 and $4 \mathrm{~g} / \mathrm{min}$ was considered as cold fluid. From all the experiments presented in that work, the one which combines $8 \mathrm{~g} / \mathrm{min}$ of supercritical water with $2 \mathrm{~g} / \mathrm{min}$ of ambient water has been considered as the basis of comparison. In this experiment, the value of the Richardson number is approximately equal to 500 indicating the predominance of natural convection over forced convection. As explained in the introduction of this work, in experiments which involve supercritical fluids, the complexity of obtaining experimental data because of the 
reduced residence times (in the order of milliseconds) and the opacity of the commercial pieces of equipment, demands innovative alternatives to the traditional techniques commonly used to study the mixing behavior. Therefore, in this case, the authors selected the neutron radiography technique which allows visualizing the interior volume of an opaque mixer and, by means of a calibration curve, obtaining the temperature profile which represents the mixing performance. The comparison between the experimental temperature profile and the theoretical one predicted by the numerical model presented in this work is shown in Figure 3:
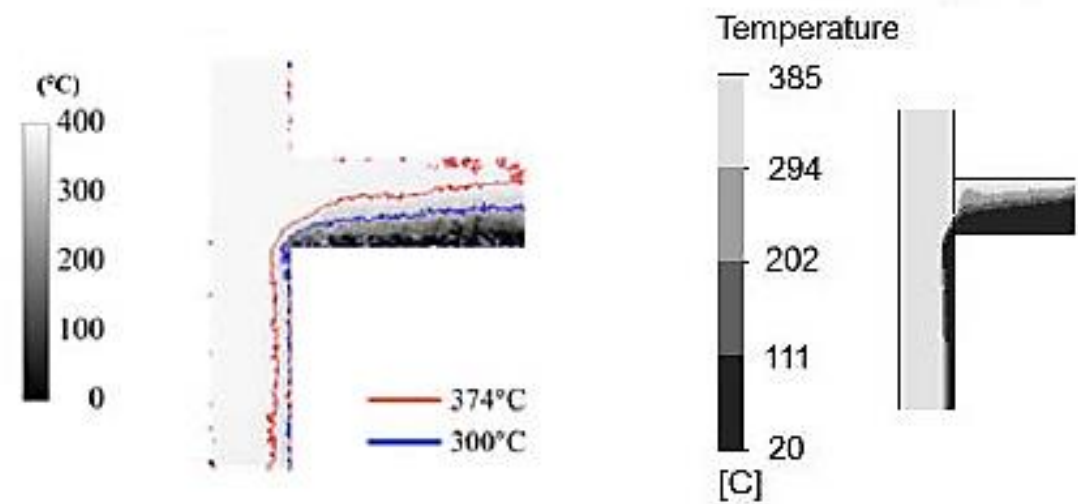

Figure 3: Comparison between the experimental temperature profile obtained by the Tohoku group [13] and the theoretical one calculated with the numerical model presented in this work. Richardson number $\mathrm{Ri} \approx 500$.

As it can be seen from Figure 3, the theoretical results predicted by the model presented in this work are in good agreement with the experimental results provided by the Tohoku University [13]. As predicted by the value of the Richardson number ( $\mathrm{Ri}=500)$, the buoyancy effects are of considerable influence in the mixing performance. The existence of strong temperature gradients creates a density stratification area which promotes natural convection generating a region of recirculation and backmixing in the ambient water inlet section. Although in the experimental profile it is observed that a 
higher fraction of supercritical water penetrates in the ambient water inlet tube, this can be explained taking into account that the simulation calculated in this work does not consider the temperature gradient along the solid wall of the mixer (since it is modeled as an adiabatic wall) which, at the mixing section of both fluid, has probably already heated up the ambient water stream. Therefore, with the experimental data, it is verified that the hot fluid does not describe a straight trajectory from its inlet to the outlet of the mixer. Moreover, once that the cold fluid enters in the outlet section, it is pushed towards the right wall of the mixer because of the forced convection effects generated by the difference between the flowrates of both streams. Regarding the turbulence regime, the value of the Reynolds number, $\operatorname{Re}=1400$, indicates that the fluid is neither in the laminar nor in the turbulent regimen and that therefore, a transition turbulence model, such as the Transition SST model, should be applied. Although the data obtained by the Tohoku group [13] considered supercritical water at $385^{\circ} \mathrm{C}$, which is lower than the temperature of the supercritical water stream selected in this work $\left(500^{\circ} \mathrm{C}\right)$, the accuracy in the predictions is enough to validate the model.

\subsection{CFD simulation results}

The theoretical analysis of the influence of the mixer configuration and of the buoyancy and turbulent effects has been performed comparing the temperature contours and the velocity streamlines obtained in the CFD simulations of the three different geometries considered in this work and presented in Figure 4 and Figure 5. Moreover, as a quantitative indicator, the area weighted average, the maximum and the minimum temperatures at the outlet of the mixers as well as the standard deviation of the temperatures in this zone have been shown in Table 2. Finally, the residence time distribution (RTD) curves of the mixers have been presented in Figure 6 in order to 
reveal the presence of dead zones and preferential pathways which are not directly observed in the temperature contours and in the velocity streamlines.

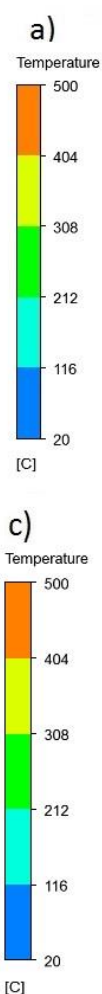

e)

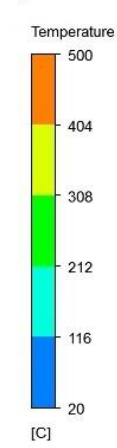

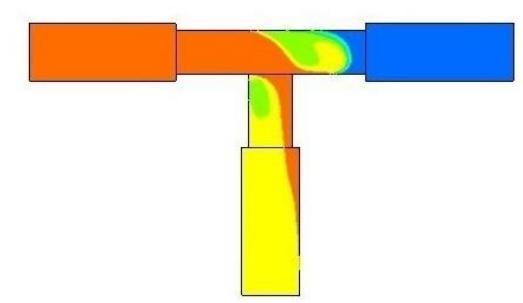
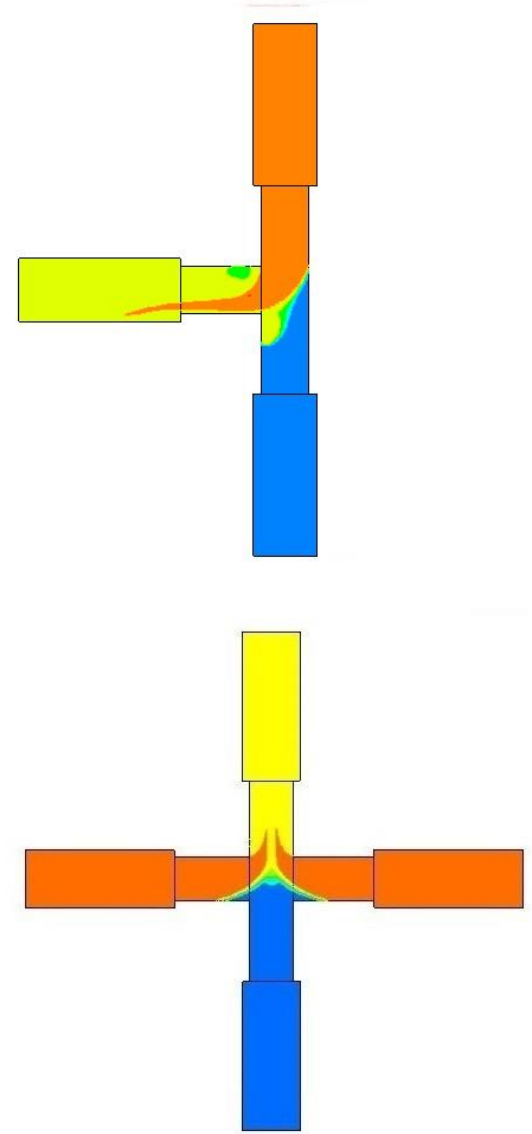

b)

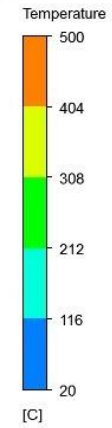

d)

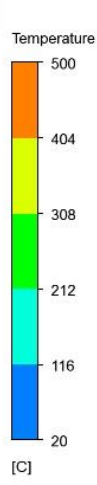

f)

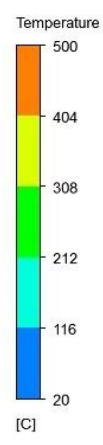

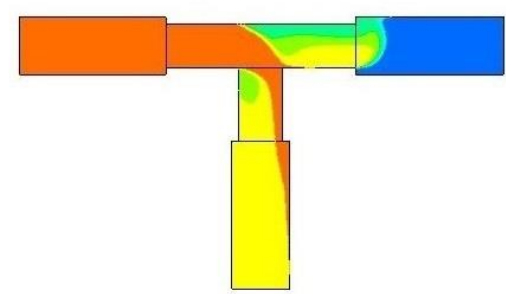
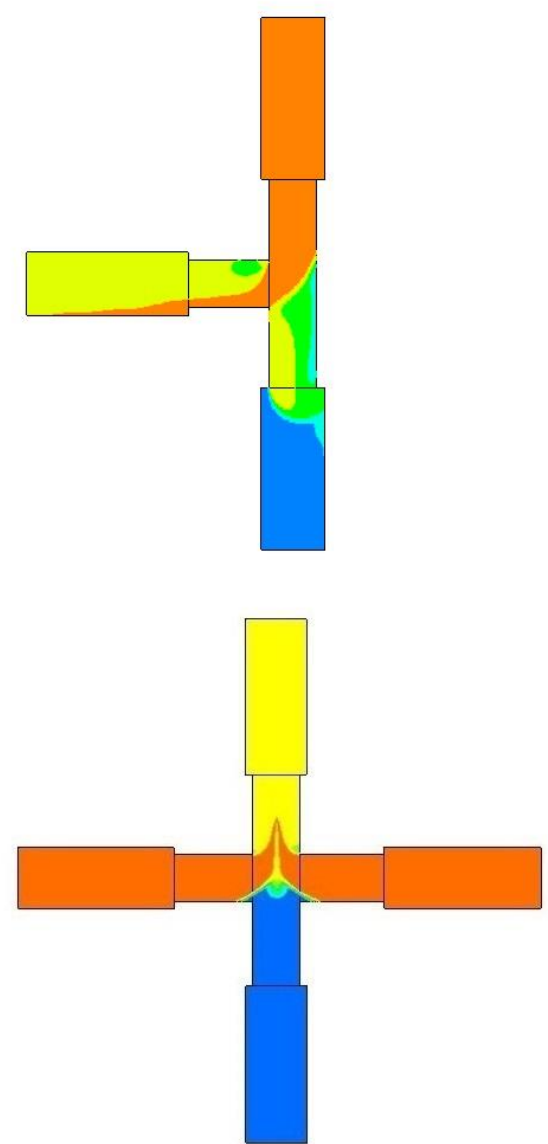

Figure 4: Temperature contours, $\left({ }^{\circ} \mathrm{C}\right)$, of the three mixer configurations analyzed in this work. a) Horizontal tee mixer, $\mathrm{Ri}=0.5$. b) Horizontal tee mixer, $\mathrm{Ri}=3 \cdot 10^{-4}$. c) Vertical tee mixer, $\mathrm{Ri}=0.5$. d) Vertical tee mixer, $\mathrm{Ri}=3 \cdot 10^{-4}$. e) Cross mixer, $\mathrm{Ri}=0.5$. f) Cross mixer, $\mathrm{Ri}=3 \cdot 10^{-4}$. 
As it can be seen from Figure 4, in the horizontal tee mixer (Figures a and b), because of the higher flow of supercritical water and as a consequence the buoyancy effects, this stream partially penetrates in the ambient water inlet section. This creates an area of recirculation and backmixing which penalizes the selectivity of the hydrolysis process because of the increase in the residence time and the existence of temperature differences which promotes lateral reactions. Apart from this area, it is observed that the reaction temperature is homogeneously reached at the outlet of the mixer. Comparing the alternatives $a$ and $b$, in alternative $b$, in which the reduced value of the Richardson number indicates a predominance of the turbulent effects, the supercritical water stream penetrates in a longer region of the ambient water inlet section than in alternative a. Therefore, it can be concluded that in this configuration, the area of recirculation and backmixing is minimized when the buoyancy effects prevail over the forced convection. The results presented in the analysis of this alternative are in accordance with the ones obtained by Sugioka et at, Aizawa et al and Blood et al [13-15] who analyzed the mixing performance in this geometry and predicted the existence of the area of recirculation and backmixing.

Regarding the second alternative in which the supercritical water and the ambient water streams are mixed in a vertical tee, the temperature profiles shown in Figure 4 are in accordance with the mixing profiles presented in previous works which analyzed this mixing configuration $[19,21]$. As it can be seen from Figure 4 and as in the previous mixing configuration, part of the supercritical water stream penetrates in the ambient water inlet section creating an area of recirculation and backmixing. Moreover, as in the horizontal mixer, the comparison between alternatives $\mathrm{c}$ and $\mathrm{d}$ concludes that increasing the velocity of the fluids increases the area of backmixing and recirculation which, as explained in the analysis of the previous configuration, penalizes the selectivity of the 
process. Finally and as in the horizontal tee mixer, the reaction temperature is homogeneously reached at the outlet of the mixer.

Finally, in the cross mixer, the analysis of the temperature contours does not reveal the existence of backmixing and recirculation areas. Moreover, as it is also proved in Table 2 , the reaction temperature is homogeneously reached at the outlet of the mixer minimizing the presence of degradation compounds at the inlet of the hydrolysis reactor. To author's knowledge, this is the first time that the effect of this type of geometry in the mixing performance is analyzed in processes which involve the use of supercritical water. The results are comparable to those presented in geometries such as the nozzle reactor [19], whose applicability to supercritical water has been recently tested again for the hydrothermal synthesis of nanoparticles [21]. However, the cross type mixer is preferred in this application because of the lower residence time.

\begin{tabular}{ccccc}
\hline Mixer & $\mathbf{X}\left({ }^{\mathbf{0}} \mathbf{C}\right)$ & $\operatorname{Max}\left({ }^{\mathbf{}} \mathbf{C}\right)$ & $\operatorname{Min}\left({ }^{\circ} \mathbf{C}\right)$ & $\boldsymbol{\sigma}\left({ }^{\mathbf{o}} \mathbf{C}\right)$ \\
\hline Horizontal Tee & 393.6 & 410.0 & 383.9 & 6.45 \\
Vertical Tee & 391.7 & 401.6 & 386.7 & 4.17 \\
Cross & 390.1 & 393.7 & 387.5 & 1.53 \\
\hline
\end{tabular}

Table 2: Temperatures at the outlet of the mixers. Mean (area weighted), maximum and minimum values and standard deviations. $\mathrm{Ri}=0.5$.

Once that the temperature contours of the three different mixing configurations presented in this work have been analyzed, the corresponding velocity streamlines are presented in Figure 5. The analysis of the velocity streamlines can corroborate the existence of areas of backmixing and recirculation clarifying the flow distribution. 
a)

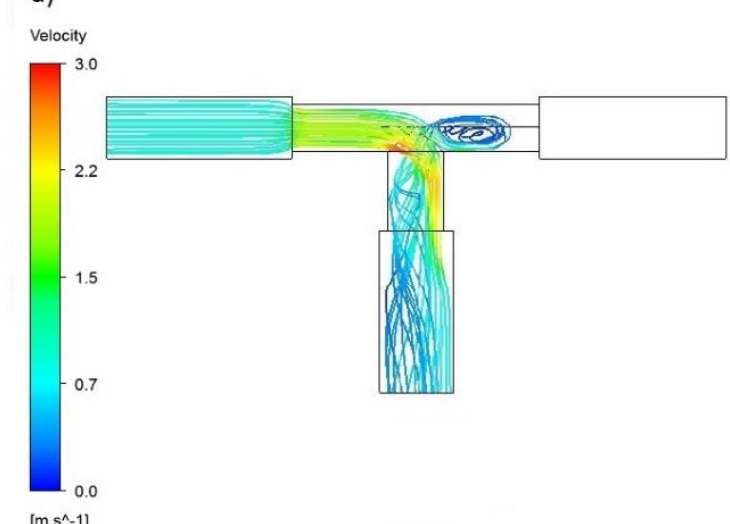

b)

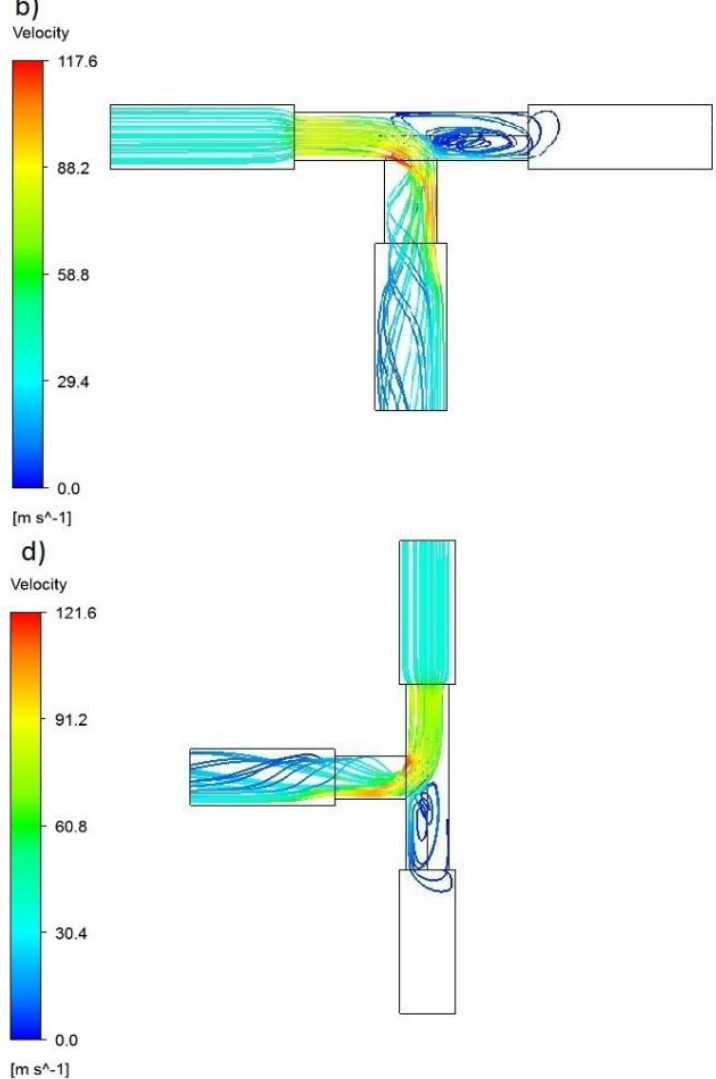

c)

Velocity

$\int_{-2.2}^{3.0}$

[m s^-1]
e)

Velocity

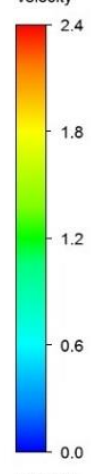

$\left[\mathrm{m} \mathrm{s}^{\wedge}-1\right]$
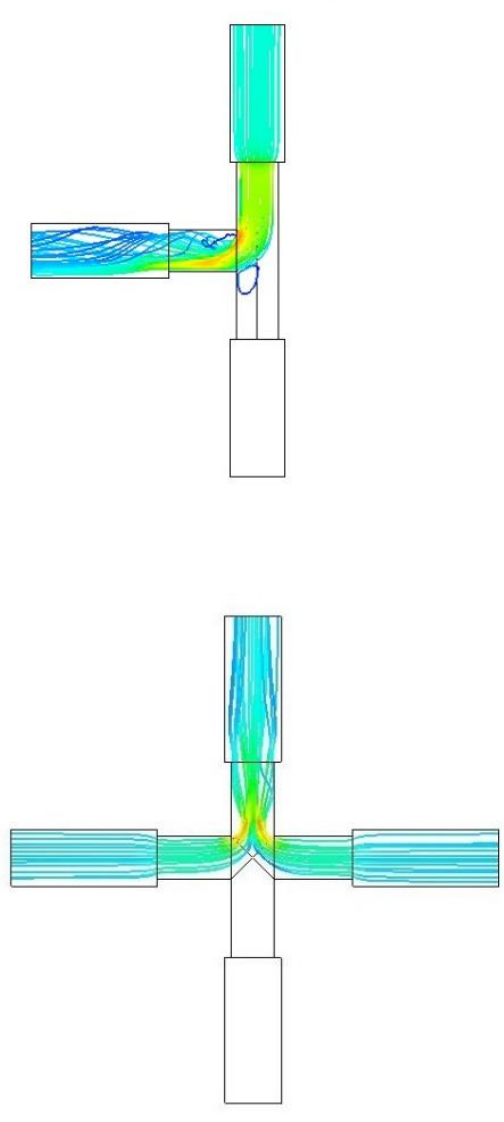

f)

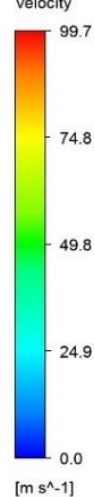

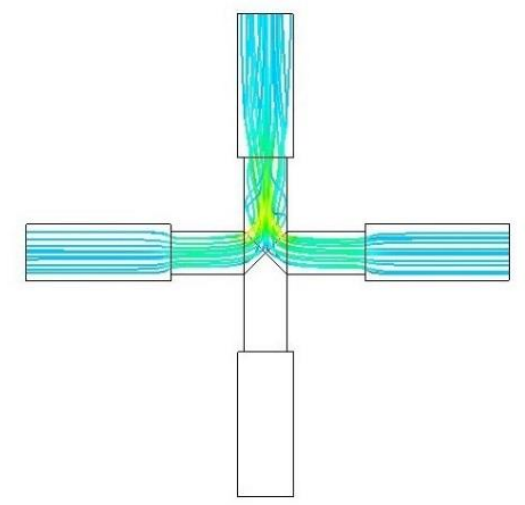

Figure 5: Analysis of the supercritical water velocity streamlines $(\mathrm{m} / \mathrm{s})$ in the three mixer configurations analyzed in this work. a) Horizontal tee mixer, $\mathrm{Ri}=0.5$. b) Horizontal tee mixer, $\mathrm{Ri}=3 \cdot 10^{-4}$. c) Vertical tee mixer, $\mathrm{Ri}=0.5$. d) Vertical tee mixer, $\mathrm{Ri}=3 \cdot 10^{-4}$. e) Cross mixer, $\mathrm{Ri}=0.5$. f) Cross mixer, $\mathrm{Ri}=3 \cdot 10^{-4}$.

As it can be seen from Figure 5, the velocity streamlines in the horizontal tee type mixer shown in Figures $a$ and $b$, confirm the existence of an area of backmixing and 
recirculation in the ambient water inlet section. Moreover, it is observed how the supercritical water is mainly concentrated in the right section of the outlet tube because of the forced convection effects. Consequently, it is expected that a considerable fraction of the biomass particles will be concentrated in the left region of the mixer outlet, which will reduce the hydrolysis rate because of the low concentration of water molecules in that zone and the agglomeration of the biomass particles. Comparing both figures, it can be seen how an increase in the velocity, and consequently in the forced convection, increases the area of backmixing and recirculation. Therefore, it is concluded that if this mixing configuration is implemented, the selection of low working velocities will improve the mixing performance.

Regarding the vertical tee mixer, the mixing behavior is quite similar to the one developed in the horizontal mixer. As in the previous case, increasing the velocity, and consequently the forced convection, increases the area of backmixing and recirculation penalizing the selectivity of the process. Moreover, as in the horizontal mixer, the trajectory of the supercritical water stream is mainly determined by its velocity. Therefore, as in the previous case, it is expected that the particles will be concentrated at the top region of the mixer outlet decreasing the hydrolysis rate.

Finally, in the cross mixer, the velocity streamlines show a homogeneous distribution of the supercritical water at the outlet of the mixer and do not reveal the existence of areas of backmixing and recirculation. Furthermore, as concluded from the analysis of the temperature profiles, the mixing performance is not influenced by the velocities of the inlet streams.

Finally, the residence time distribution (RTD) curves of the mixers, obtained after the simulation of the impulse experiment, are presented in Figure 6. A detailed evaluation 
of these curves can reveal the existence of preferential pathways and dead zones which, in some cases, cannot be directly observed from the temperature contours and the velocity streamlines:

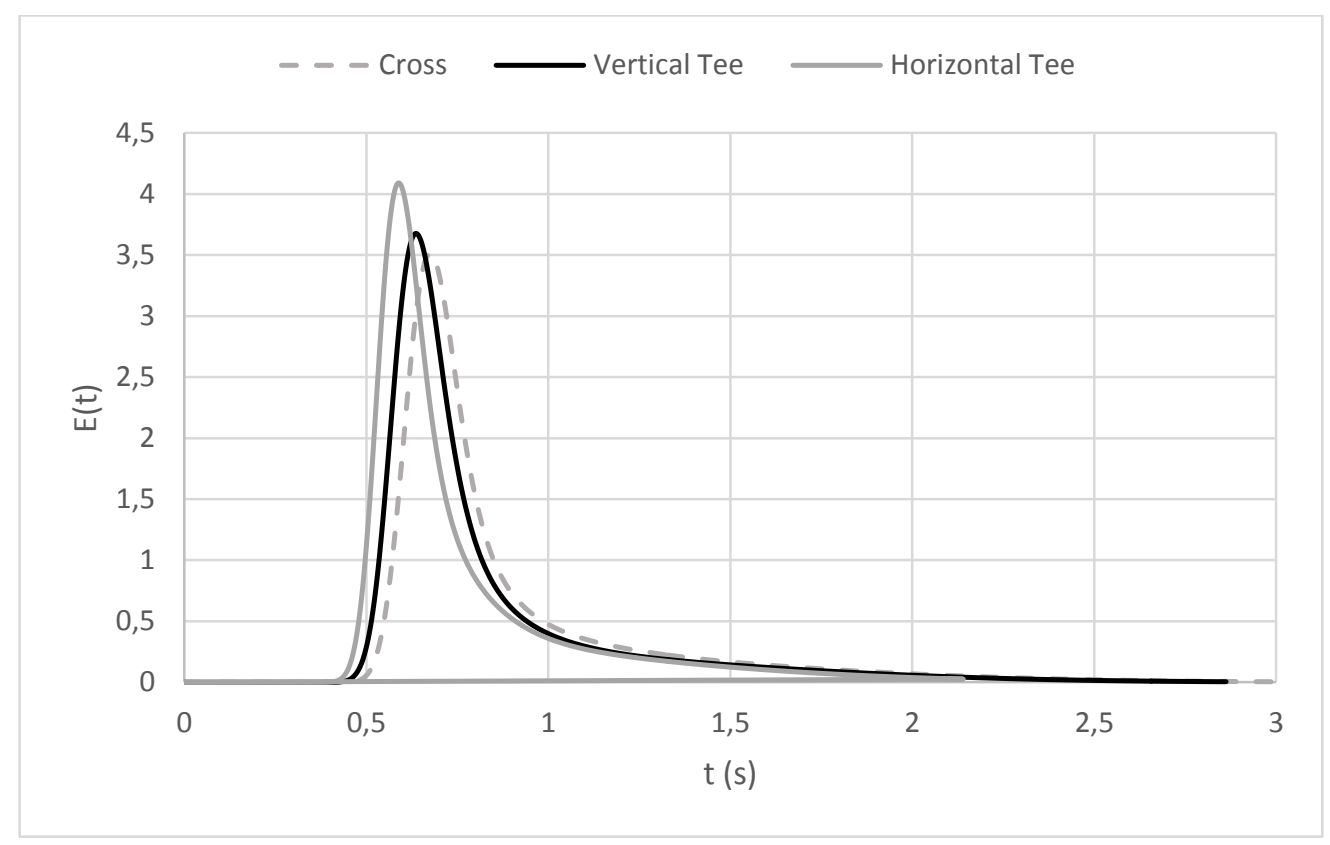

Figure 6: Residence time distribution curves. (- -) Mixing cross. (-) Vertical Tee. (-) Horizontal Tee. $\mathrm{Ri}=0.5$.

As it can be seen from the graphs, apart from the final tails which indicate a deviation originated by a dead zone, the RTD curves show a predominance of plug flow. Although the mean residence times vary from $0.76 \mathrm{~s}$ in the case of the horizontal tee to 0.89s in the case of the cross mixers, the high influence of the dead zones along with the high density and the low flowrate of the biomass inlet stream explain the increase in this parameter. While in the case of the horizontal and the vertical tees the dead zones can be clearly seen in the temperature contours and in the velocity streamlines, in the case of the cross mixer, the dead zone, which is not observed neither in the temperature contours nor in the velocity streamlines is located in the vicinities of the mixing section. 
To quantify the influence of the dead zones in the mean residence time, the degree of stagnancy S(c.tr) [29], defined as the fraction of fluid which remains in the mixers for a time longer than c times the mean residence time, has been calculated (Table 3 ). In this work a value of c equal to 2 has been selected:

\begin{tabular}{ccc}
\hline Mixer & $\operatorname{tr}(\mathbf{s})$ & $\mathbf{S}(\mathbf{2 t r})$ \\
\hline Horizontal Tee & 0.76 & 0.09 \\
Vertical Tee & 0.83 & 0.12 \\
Cross & 0.89 & 0.11 \\
\hline
\end{tabular}

Table 3: Mean residence time (tr) \& degree of stagnancy $(S(2 \operatorname{tr})) . R i=0.5$.

As it can be seen from Table 3, no remarkable differences are found between the degrees of stagnancy of the mixers proving that the influence of the dead zones is similar in all the cases.

The theoretical analysis of the mixing performance shows that, because of the better homogenization of the temperature at the outlet of the mixer and the similarities between the RTD curves of the mixers, the implementation of a mixing cross is preferred.

\section{Conclusions}

In this work, the influence of the mixer geometry on the mixing performance in the process of biomass ultrafast hydrolysis by supercritical was analyzed. The mixing behavior was studied comparing the experimental results obtained in the hydrolysis plant of our research group with the temperature contours, the velocity streamlines and the RTD curves generated in the CFD simulations of the three mixers selected, a horizontal mixing tee, a vertical mixing tee and a mixing cross. Although slightly higher 
conversion were obtained in those experiments performed with a horizontal tee, the small differences between the results demanded a theoretical analysis of the mixing performance. Therefore, according to the CFD simulation results, since the mixing cross provided the best temperature homogenization and flow distribution at the outlet of the mixers and, because of the similarities in the residence time distribution curves of the mixers, this mixing geometry was considered as the optimum to perform the mixing between the biomass suspension stream and the supercritical water stream.

\section{Appendix 1}

This appendix presents the temperature profiles of additional mixing configurations which have not been considered in this work because of their lower mixing efficiency. Additionally, Table A1 shows a quantitative analysis of the mixing efficiency by means of the area weighted average, maximum and minimum temperatures at the outlet of each mixer as well as the standard deviations between the temperature values in this zone.

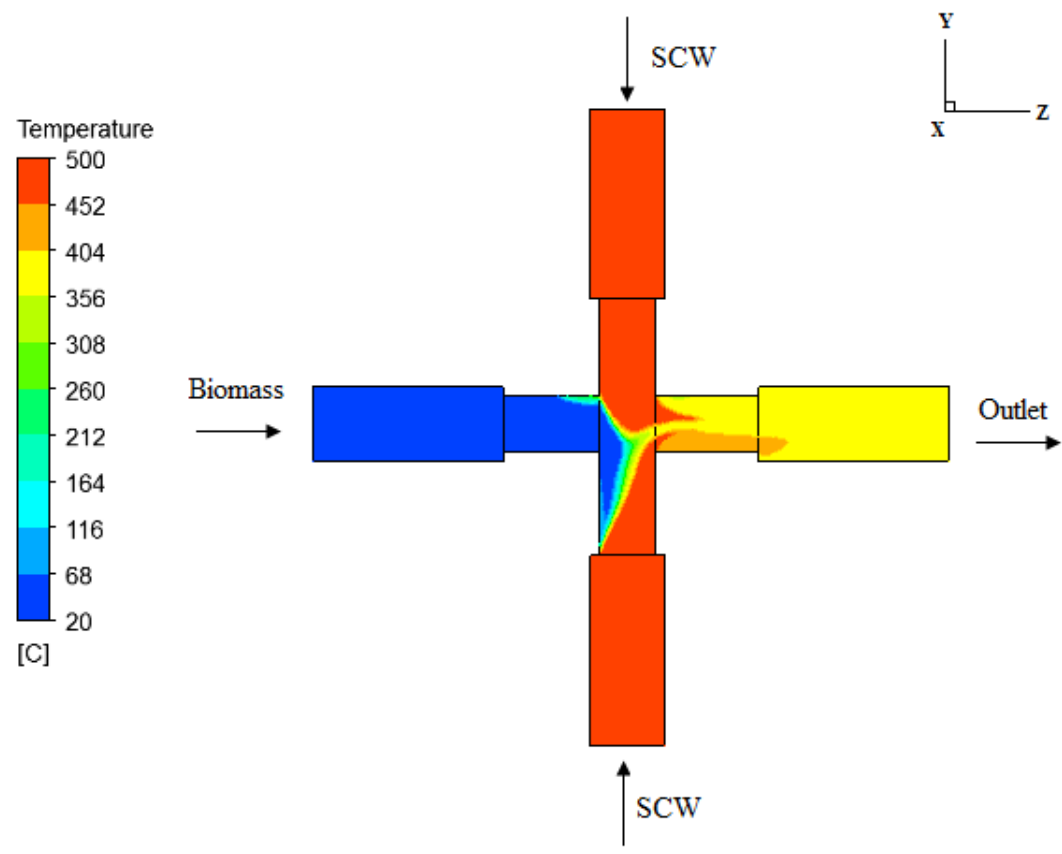

Figure A1: Mixer A1, temperature contour $\left({ }^{\circ} \mathrm{C}\right)$. 


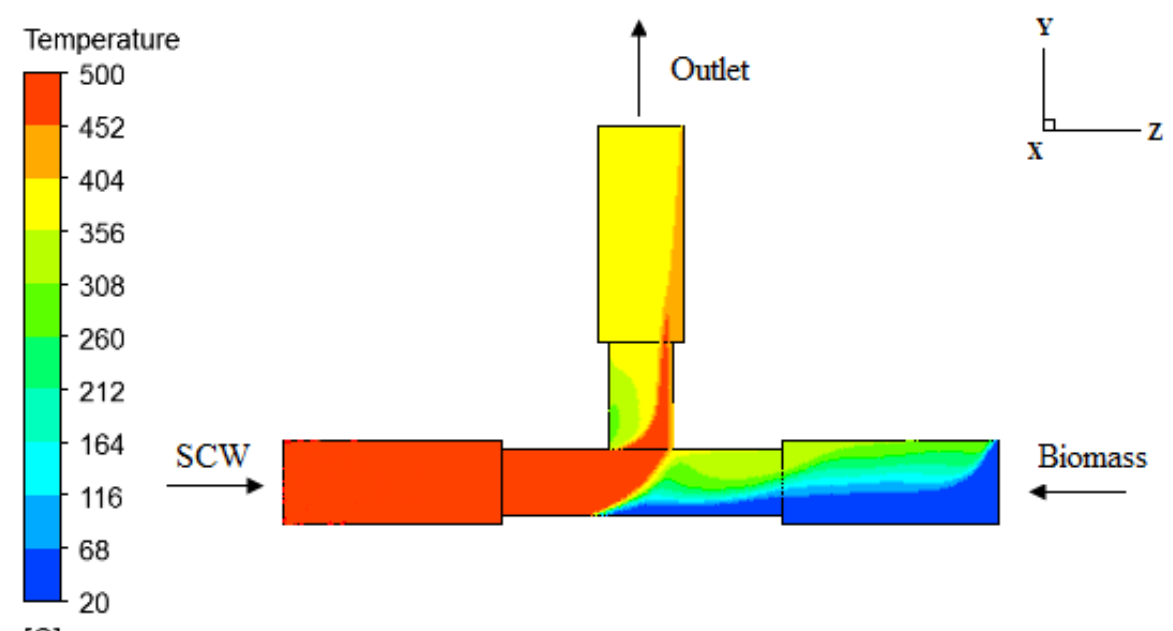

[C]

Figure A2: Mixer A2, temperature contour $\left({ }^{\circ} \mathrm{C}\right)$.

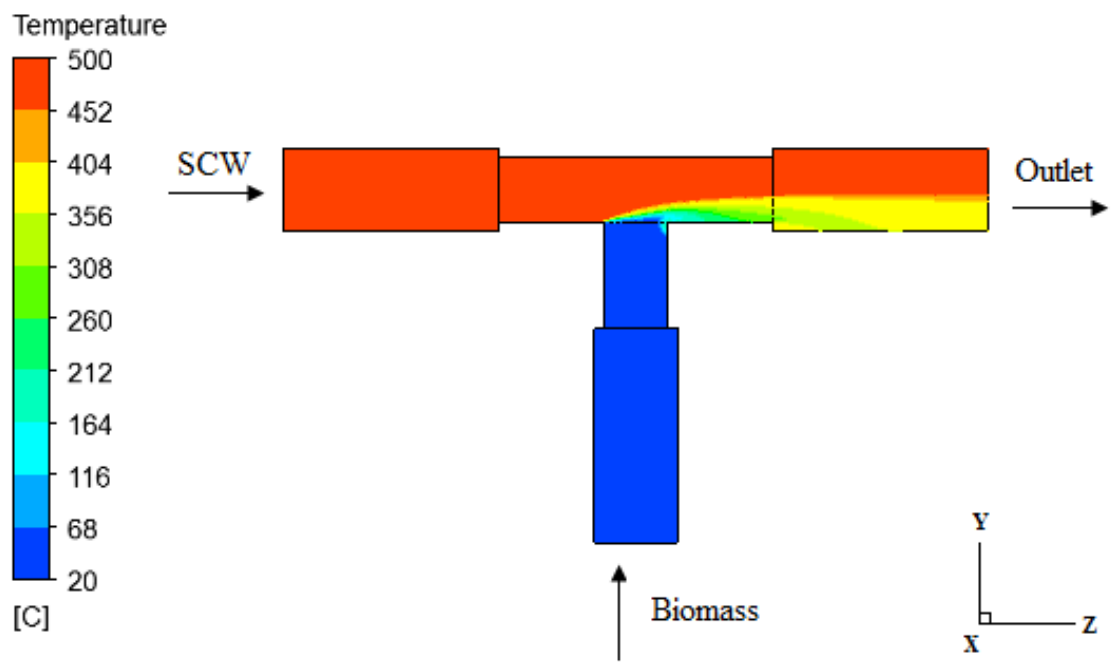

Figure A3: Mixer A3, temperature contour $\left({ }^{\circ} \mathrm{C}\right)$. 


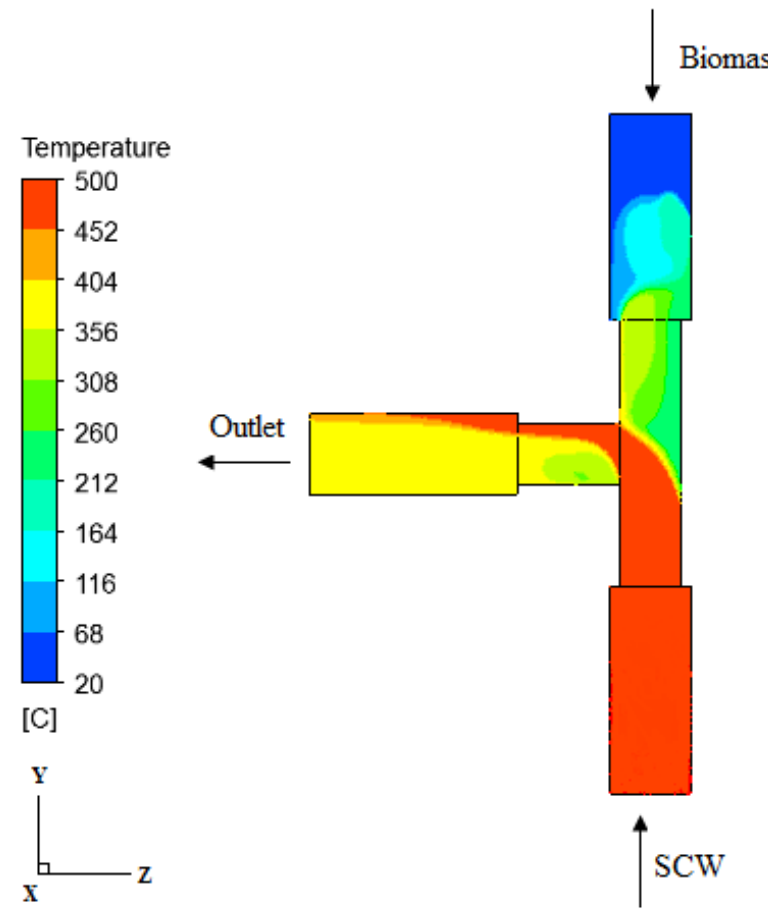

Figure A4: Mixer A4, temperature contour $\left({ }^{\circ} \mathrm{C}\right)$.
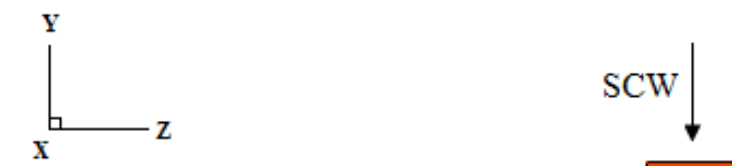

Temperature

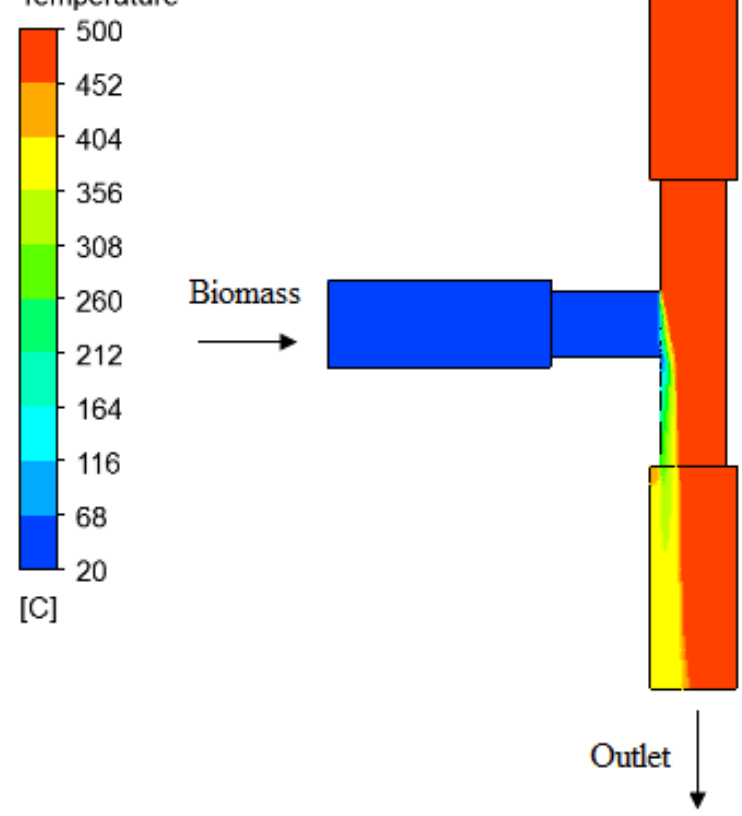

Figure A5: Mixer A5, temperature contour $\left({ }^{\circ} \mathrm{C}\right)$. 


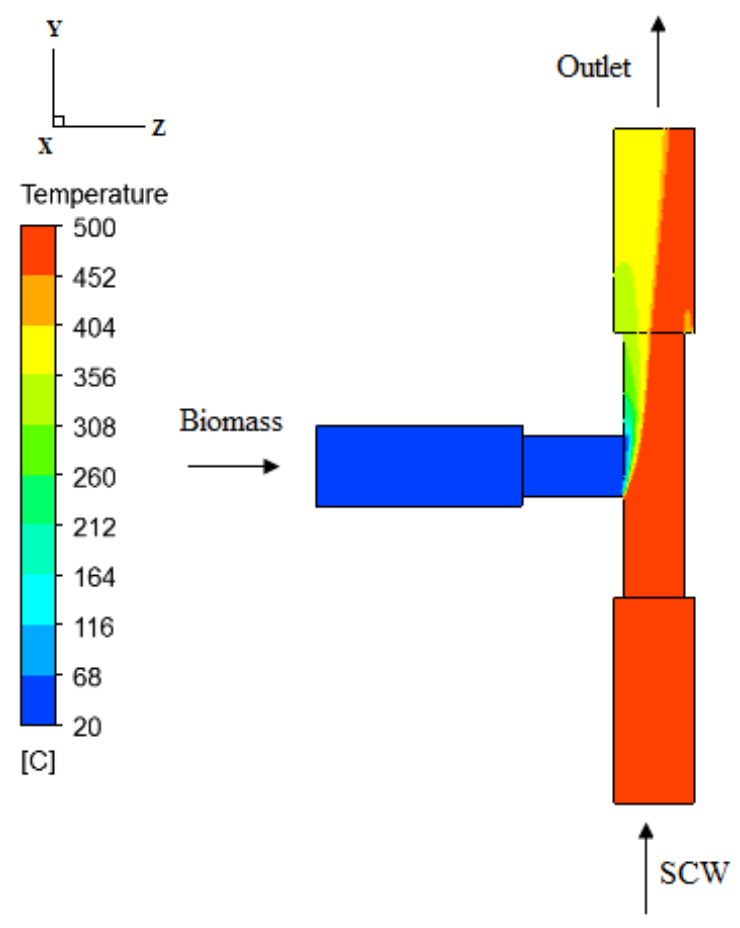

Figure A6: Mixer A6, temperature contour $\left({ }^{\circ} \mathrm{C}\right)$.

\begin{tabular}{ccccc}
\hline Mixer & $\mathbf{X}\left({ }^{\mathbf{}} \mathbf{C}\right)$ & Maximum $\left({ }^{\mathbf{0}} \mathbf{C}\right)$ & Minimum $\left({ }^{\mathbf{O}} \mathbf{C}\right)$ & $\boldsymbol{\sigma}\left({ }^{\circ} \mathbf{C}\right)$ \\
\hline A1 & 389.9 & 394.3 & 295.5 & 7.72 \\
A2 & 390.7 & 410.2 & 386.0 & 5.78 \\
A3 & 431.0 & 499.7 & 367.5 & 50.56 \\
A4 & 393.4 & 433.5 & 385.2 & 11.01 \\
A5 & 452.1 & 499.9 & 379.3 & 50.14 \\
A6 & 408.3 & 491.0 & 379.8 & 37.65 \\
\hline
\end{tabular}

Table A1: Temperatures at the outlet of the mixers. Mean (area weighted), maximum and minimum values and standard deviations.

\section{Acknowledgements}

The authors thank MINECO and FEDER program for the financial support Projects CTQ2013-44143-R and CTQ2016-79777-R, 


\section{References}

[1] M.J. Cocero, Á. Cabeza, N. Abad, T. Adamovic, L. Vaquerizo, C.M. Martínez, M.V. Pazo-Cepeda, Understanding biomass fractionation in subcritical \& supercritical water, J. Supercrit. Fluids. 133 (2018) 550-565.

[2] G. Brunner, Processing of Biomass with Hydrothermal and Supercritical Water, in: Supercrit. Fluid Sci. Technol., 2014: pp. 395-509.

[3] D.A. Cantero, M. Dolores Bermejo, M. José Cocero, High glucose selectivity in pressurized water hydrolysis of cellulose using ultra-fast reactors, Bioresour. Technol. 135 (2013) 697-703.

[4] G. Brunner, Near critical and supercritical water. Part I. Hydrolytic and hydrothermal processes, J. Supercrit. Fluids. 47 (2009) 373-381.

[5] T. Adschiri, Biomass Conversion in Supercritical Water, in: Supercrit. Fluid Technol. Energy Environ. Appl., 2014: pp. 89-98.

[6] D.A. Cantero, M.D. Bermejo, M.J. Cocero, Kinetic analysis of cellulose depolymerization reactions in near critical water, J. Supercrit. Fluids. 75 (2013) $48-57$.

[7] M. Sasaki, T. Adschiri, K. Arai, Kinetics of Cellulose Conversion at $25 \mathrm{MPa}$ in Sub- and Supercritical Water, AIChE J. 50 (2004) 192-202.

[8] M. Sasaki, M. Furukawa, K. Minami, T. Adschiri, K. Arai, Kinetics and mechanism of cellobiose hydrolysis and retro-aldol condensation in subcritical and supercritical water, Ind. Eng. Chem. Res. 41 (2002) 6642-6649.

[9] C.M. Martínez, D.A. Cantero, M.D. Bermejo, M.J. Cocero, Hydrolysis of cellulose in supercritical water: reagent concentration as a selectivity factor, Cellulose. 22 (2015) 2231-2243. 
[10] C.M. Martínez, T. Adamovic, D.A. Cantero, M.J. Cocero, Scaling up the production of sugars from agricultural biomass by ultrafast hydrolysis in supercritical water, J. Supercrit. Fluids. 143 (2019) 242-250.

[11] D.A. Cantero, L. Vaquerizo, F. Mato, M.D. Bermejo, M.J. Cocero, Energetic approach of biomass hydrolysis in supercritical water, Bioresour. Technol. 179 (2015) 136-143.

[12] L. Vaquerizo, M.J. Cocero, A green desuperheater for an energetic efficient alternative to the decompression valve in biomass supercritical water ultrafast hydrolysis process, J. Supercrit. Fluids. 133 (2018) 704-715.

[13] K. ichi Sugioka, K. Ozawa, T. Tsukada, S. Takami, T. Adschiri, K. Sugimoto, N. Takenaka, Y. Saito, Neutron radiography and numerical simulation of mixing behavior in a reactor for supercritical hydrothermal synthesis, AIChE J. 60 (2014) 1168-1175.

[14] T. Aizawa, Y. Masuda, K. Minami, M. Kanakubo, H. Nanjo, R.L. Smith, Direct observation of channel-tee mixing of high-temperature and high-pressure water, J. Supercrit. Fluids. 43 (2007) 222-227.

[15] P.J. Blood, J.P. Denyer, B.J. Azzopardi, M. Poliakoff, E. Lester, A versatile flow visualisation technique for quantifying mixing in a binary system: Application to continuous supercritical water hydrothermal synthesis (SWHS), Chem. Eng. Sci. 59 (2004) 2853-2861.

[16] T. Huddle, A. Al-Atta, S. Moran, E. Lester, Pseudo fluid modelling used in the design of continuous flow supercritical water oxidation reactors with improved corrosion resistance, J. Supercrit. Fluids. 120 (2017) 355-365.

[17] A. Raghavan, A.F. Ghoniem, Simulation of supercritical water-hydrocarbon mixing in a cylindrical tee at intermediate Reynolds number: Impact of 
temperature difference between streams, J. Supercrit. Fluids. 95 (2014) 325-338.

[18] J. Sierra-Pallares, D.L. Marchisio, E. Alonso, M.T. Parra-Santos, F. Castro, M. José Cocero, Quantification of mixing efficiency in turbulent supercritical water hydrothermal reactors, Chem. Eng. Sci. 66 (2011) 1576-1589.

[19] E. Lester, P. Blood, J. Denyer, D. Giddings, B. Azzopardi, M. Poliakoff, Reaction engineering: The supercritical water hydrothermal synthesis of nanoparticles, J. Supercrit. Fluids. 37 (2006) 209-214.

[20] L.L. Toft, D.F. Aarup, M. Bremholm, P. Hald, B.B. Iversen, Comparison of Tpiece and concentric mixing systems for continuous flow synthesis of anatase nanoparticles in supercritical isopropanol/water, J. Solid State Chem. 182 (2009) $491-495$.

[21] J. Sierra-Pallares, T. Huddle, J. García-Serna, E. Alonso, F. Mato, I. Shvets, O. Luebben, M.J. Cocero, E. Lester, Understanding bottom-up continuous hydrothermal synthesis of nanoparticles using empirical measurement and computational simulation, Nano Res. 9 (2016) 3377-3387.

[22] B.D. Phenix, J.L. DiNaro, J.W. Tester, J.B. Howard, K.A. Smith, The effects of mixing and oxidant choice on laboratory-scale measurements of supercritical water oxidation kinetics, Ind. Eng. Chem. Res. 41 (2002) 624-631.

[23] L. Vaquerizo, N.A. Fernández, R.B. Mato, M.J. Cocero, Redefining conventional biomass hydrolysis models by including mass transfer effects. Kinetic model of cellulose hydrolysis in supercritical water., Chem. Eng. J. 350 (2018) 463-473.

[24] L. Vaquerizo, M.J. Cocero, CFD-Aspen Plus interconnection method. Improving thermodynamic modeling in computational fluid dynamic simulations, Comput. Chem. Eng. 113 (2018) 152-161.

[25] B.J. McKeon, C.J. Swanson, M. V. Zagarola, R.J. Donnelly, A.J. Smits, Friction 
factors for smooth pipe flow, J. Fluid Mech. 511 (2004) 41-44.

[26] ANSYS, Ansys Fluent User Guide, Release 15, 2013.

[27] J. Bardina, P. Huang, T. Coakley, J. Bardina, P. Huang, T. Coakley, Turbulence modeling validation, in: 28th Fluid Dyn. Conf., 1997.

[28] P. V. Danckwerts, Continuous flow systems. Distribution of residence times, Chem. Eng. Sci. 2 (1953) 1-13.

[29] B.A. Robinson, J.W. Tester, Characterization of flow maldistribution using inletoutlet tracer techniques: An application of internal residence time distributions, Chem. Eng. Sci. 41 (1986) 469-484. 